\title{
EQUILIBRIUM CONDITIONS IN THE SYSTEM CARBON, IRON OXIDE, AND HYDROGEN IN RELATION TO THE LEDEBUR METHOD FOR DETERMINING OXY- GEN IN STEEL
}

\author{
By J. R. Cain and Leon Adler
}

CONTENTS

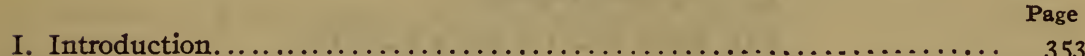

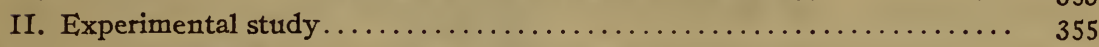

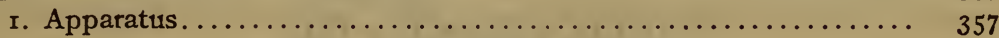

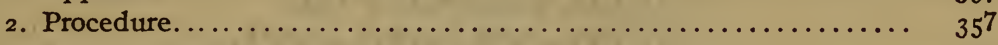

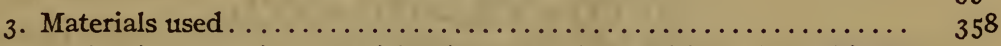

4. Reduction experiments with mixtures of iron oxide and graphiteConstant rate of passing hydrogen................... 359

5. Reduction experiments with mixtures of iron oxide and iron containing iron carbide-(combined carbon) - Constant rate of passing

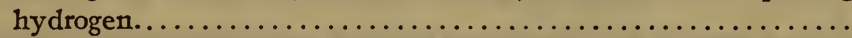

6. Reduction experiments with mixtures of iron oxide and chilled cast iron, partially annealed and unannealed-Constant rate of passing

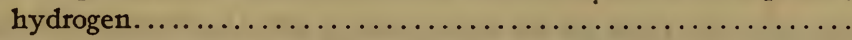

7. Reduction experiments with mixtures of unannealed cast iron and iron oxide-Rate of passing hydrogen varied...............

8. Investigations concerning the oxygen not evolved as water in the preceding experiments........................... $3^{62}$

9. Oxygen determinations by the Ledebur method on the same steels with varying rates of hydrogen $\ldots \ldots \ldots \ldots \ldots \ldots \ldots \ldots \ldots \ldots, \quad 365$

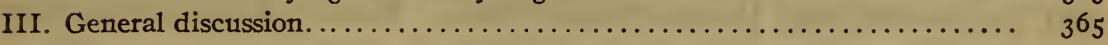

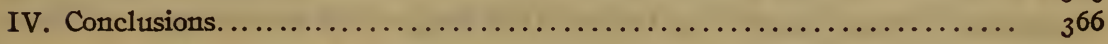

\section{INTRODUCTION}

Ledebur's method ${ }^{1}$ for determining oxygen in steel and iron is carried out by heating chips of the metal to $900^{\circ}$ in a current of hydrogen and weighing the water formed by the (type) reaction (I) $\mathrm{FeO}+\mathrm{H}_{2}=\mathrm{Fe}_{2}+\mathrm{H}_{2} \mathrm{O}$. If oxides of other metals are present these may or may not be affected. ${ }^{2}$

In order that the results shall be accurate, it is essential that (I) the reduction shall be performed only by hydrogen, and not by the carbon present in the steel; (2) the water vapor formed shall not be decomposed by secondary reactions before it is weighed;

1 Ledebur, Leitfaden fur Eisenhütten Laboratorien, gth Aufl., p. I54.

- Cain and Pettijohn, Bureau of Standards Technical Paper No. Ir8; 19x9. $134145^{\circ}-19$ 
(3) conditions must be chosen so that the equilibrium of reaction

(I) is shifted as far as possible toward the right.

How complicated reaction (r) may be when applied to steeli. e., an iron-carbon system instead of iron only-can be seen by inspection of equations 2 to 9 inclusive, which describe various interreactions that are possible in the gaseous phase or between gaseous and solid phases in the system iron, iron oxide, carbon, and hydrogen at $900^{\circ}$.

Reactions:
(2) $\mathrm{FeO}+\mathrm{C} \rightleftarrows \mathrm{Fe}+\mathrm{CO}$
(3) $\mathrm{FeO}+\mathrm{CO} \rightleftarrows \mathrm{Fe}+\mathrm{CO}_{2}$
(4) ${ }_{2} \mathrm{CO} \rightleftarrows \mathrm{CO}_{2}+\mathrm{C}$
(5) $\mathrm{Fe}+\mathrm{YCO}=\mathrm{FeC}_{5}+\mathrm{XCO}_{2}$ $\left(\mathrm{Fe}_{3} \mathrm{C}\right.$ ?)
(6) $\mathrm{CO}_{2}+\mathrm{H}_{2} \rightleftarrows \mathrm{CO}+\mathrm{H}_{2} \mathrm{O}$
(7) $\mathrm{CO}+\mathrm{YH}_{2} \rightleftarrows \mathrm{H}_{2} \mathrm{O}+\mathrm{XCH}_{\mathrm{y}}$
(8) $\mathrm{C}+\mathrm{H}_{2} \mathrm{O} \rightleftarrows \mathrm{CO}+\mathrm{H}_{2}$
(9) $\mathrm{C}+\mathrm{H}_{2}=\mathrm{XCH}_{\mathbf{y}}$
(Io) $2 \mathrm{H}_{2} \mathrm{O} \rightleftarrows 2 \mathrm{H}_{2}+\mathrm{O}_{2}$

Ledebur seems to have overlooked or disregarded these reactions when he devised his method, and the present work was undertaken to give information as to their effect on the results obtainable by the Ledebur method when certain variables are introduced into it. These reactions have been studied from different angles by many workers, but usually the conditions of their investigations are so different from those described herein that not many conclusions can be drawn from the previous work. However, certain deductions can be made with a reasonable degree of certainty.

Langmuir's work ${ }^{3}$ shows that the thermal dissociation of water into hydrogen and oxygen (equation ro) is negligible at $900^{\circ}$ to $1000^{\circ}$.

Reaction (2) was investigated by Schenk and Heller ${ }^{4}$ with regard to the specific effect of different forms of carbon. They found that amorphous carbon was more active than graphite in reducing iron oxide. Falcke ${ }^{5}$ states that reactions (2) and (3) proceed together and begin at $500^{\circ}$ to $600^{\circ}$.

Reaction (4) has been investigated by Rhead and Wheeler ${ }^{\circ}$, Fay and Seeker, ${ }^{7}$ and others. The study of this reaction is usually

\footnotetext{
${ }^{3}$ Irving Langmuir, J. Am. Chem. Soc., 28, p. 1357; 1906.

4 Ber., 38, p. 2139: 1905.

6 Falcke, Z. Electrochemie, 21, pp. 37-50, 1915; 22, pp. 121-133; 1916; Ber., 46, pp. 743-750.

${ }^{6}$ Rhead and Wheeler, J. Chem. Soc., 97, p. 2178 , I9ro; 99, p. I140, 191r; 101, p. 83 I, 1912.

' Fay and Seeker, J. Am. Chem. Soc., 25, p. 640; 1903.
} 
connected. with investigations of reactions (2) and (3), since reduced metals and their oxides catalyze these reactions in one direction or the other.

The principal results of these researches that concern the present investigation are (I) that reaction (4) takes place toward the right only at temperatures below $1000^{\circ}$; (2) that the speed of the reaction is greatly affected by temperature; for instance at $80^{\circ}$ it is 66 times as fast as the reverse reaction (Rhead and Wheeler loc. cit.); (3) that the reduced iron and unreduced oxide both catalyze the reverse reaction; (4) that the speed of the gas current through the apparatus or over the catalyzers is of great importance.

Reaction (5) has been investigated by Giolitti ${ }^{8}$ in connection with casehardening experiments. His book on casehardening gives many other references. This reaction proceeds rapidly above $810^{\circ} \mathrm{C}$.

Reaction (6) has been studied by O. Hahn ${ }^{\circ}$ and by Boudouard; ${ }^{10}$ reaction (8) has also been studied by $\mathrm{O}$. Hahn. ${ }^{11}$ The reduction of carbon monoxide by hydrogen, where water is the only reaction product instead of hydrocarbons, as indicated in reaction (7), has been studied by Gautier. The reduction of carbon dioxide by hydrogen takes place at temperatures as low as $400^{\circ}$.

Reaction (8) has been frequently investigated in connection with gas-producer studies; the reduction of water vapor by carbon begins at about $600^{\circ}$ and is very rapid at $1100^{\circ}$.

The formation of hydrocarbons from interaction of carbon and hydrogen (reaction 9) has been studied by the authors and mentioned by others. Such reactions are easily possible under the conditions prescribed by Ledebur, and they took place in some of the experiments described later in this paper.

\section{EXPERIMENTAL STUDY}

To study the relation of these reactions to the Ledebur method, a series of experiments was made in which mixtures of iron oxide and iron containing iron carbide or of iron and various forms of carbon were heated to $900^{\circ}$ in pure hydrogen. The proportions of the mixtures and the rates of passage of the hydrogen were varied in a systematic way, and the reaction products were collected and studied.

8 Giolitti, F., Cementation of Iron and Steel (translated by Richards and Roniller), Graw-Hill Book Co., N. Y.; I915.

O. Hahn, Z. Physik. Chem., 42, p. 705, 1903; 44, p. 513, 1903; 48, p. 735 ; 1904.

${ }^{10} \mathrm{M}$. Boudouard, Bul. Soc. Chim., $3 \mathrm{~d}$ series, 25,484 ; $190 \mathrm{r}$.

"Loc. cit. 


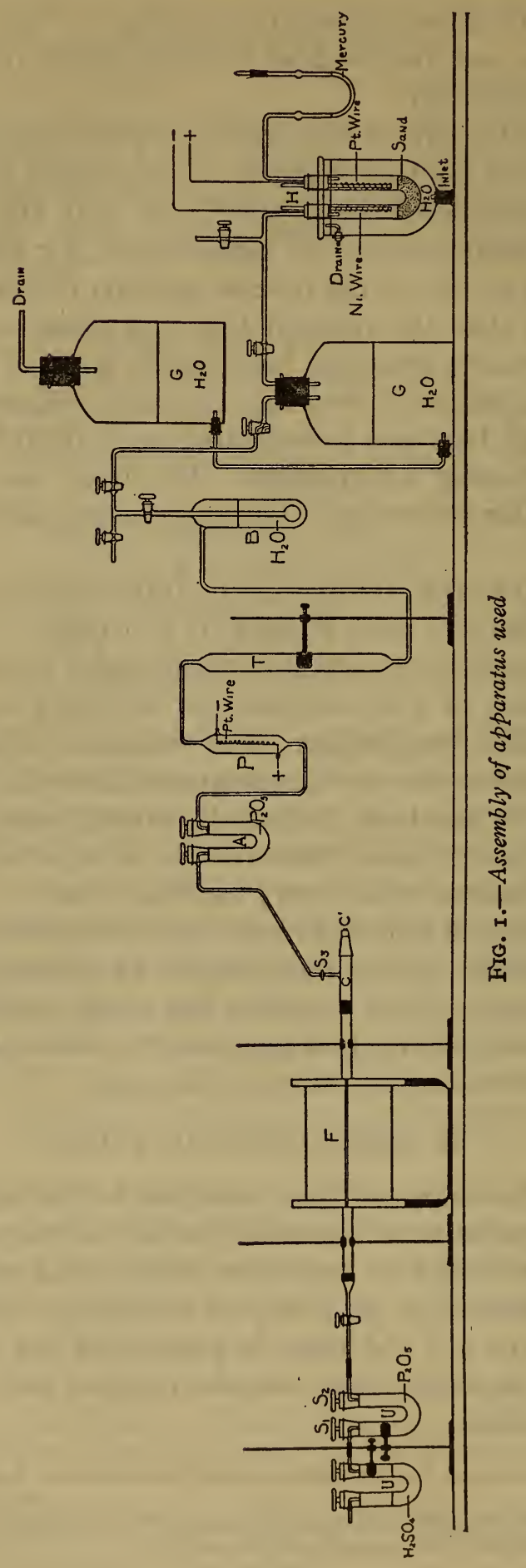




\section{APPARATUS}

The apparatus used is shown in Fig. I. It consists of the electrolytic hydrogen generator $(H)$ with reservoirs $G$, followed by bubble counter $B$ and calcium chloride lower $T$, the preheater $P$ and its absorber $(A)\left(\mathrm{P}_{2} \mathrm{O}_{5}\right)$ for removing traces of oxygen from the hydrogen, the furnace and combustion tube $(F)$ for heating the mixtures (which are contained in quartz boats), phosphorous pentoxide tubes $(U)$ for collecting the water formed, and sulphuric acid guard tube $U^{\prime}$. When carbon dioxide was to be determined, a Meyer tube containing barium hydroxide was used to collect it; the precipitated barium carbonate was filtered off and titrated. The apparatus for determining carbon monoxide followed. This is described in detail later in this paper. The electrolytic hydrogen generator and its purifying apparatus, and also the special electric furnace, are illustrated and described elsewhere. ${ }^{12}$

The glass tube $(C)$ was cemented on the porcelain combustion tube with De Khotinsky cement; the ground-glass cap $\left(C^{1}\right)$ could be removed and a boat introduced without removing $C$. With a little care in lubrication of $\left(C^{1}\right)$ this device was found very satisfactory. By suitable manipulation of the stopcocks at either end of the combustion tube, it could be freed of air by alternately evacuating (an efficient water aspirator was found very satisfactory) and filling with hydrogen. Two evacuations and replacements with hydrogen reduced the residual oxygen (from air) to less than $0.000022 \mathrm{~g}$, provided the aspiration reduced the pressure to $20 \mathrm{~mm}$ mercury. Any good aspirator will do this at moderate room temperatures; at higher temperatures prevailing in summer a vacuum of $30 \mathrm{~mm}$ mercury is obtained. This would leave $0.00009 \mathrm{~g}$ oxygen in the tube after two evacuations. The effect of such quantities of oxygen is negligible in the present work. The temperature of the furnace was determined every few days with a thermocouple and held at $900^{\circ}$ by maintaining a constant current.

\section{PROCEDURE}

The boat containing the mixture being tested was placed in the furnace and the residual oxygen and water vapor removed as described. The current was then turned on the furnace and the purified hydrogen admitted; the rate of passage of this current was kept constant and was calculated from the total volume used (determined from the change of height of the water in $G$ ) divided 
by the time it was passed. The heating of the tube to $900^{\circ}$ from room temperature required about 20 minutes. The average time required for an operation was $I / 2$ hours. At the conclusion of an experiment the current was shut off from the furnace and cocks $S_{1}$ and $S_{2}$ were closed; the phosphorous pentoxide tube was disconnected and weighed after standing in the balance one-half hour. Many experiments were made with the different types of reduction described later, in order to be certain that all reduction products had been removed from the furnace in the allotted time; these tests were made by connecting a second phosphorous pentoxide tube and aspirating during another half hour. In all cases, except a group of experiments where very low rates of hydrogen were used, the gain in weight of the second tube was negligible (o.OI to $0.02 \mathrm{mg}$ ). The difficulty just mentioned in the case of low rates of hydrogen passage was met by removing the vapor by exhausting the whole system back to cock $S_{3}$. This was done with a water aspirator and was so effective that all the water from a reaction was absorbed by the phosphorous pentoxide tube in to minutes. This tube was inclosed in an outer vessel (a vacuum desiccator), also evacuated, so as to prevent collapse of its thin walls. A number of blank determinations made according to the procedure above described, but with no substance in the boat, showed them to be negligible (less than o.I mg). These blank determinations were made at frequent intervals and the results were always below the limit stated except with very high rates of hydrogen admission. This was probably because the catalyzer had insufficient capacity to completely remove the oxygen impurity at these rates. However, the correction necessary even in such cases was very small (about I per cent of the total water weighed).

\section{MATERIALS USED}

(a) Magnetite Ore, Bureau of Standards Analyzed Sample No. 29.-Certificate analysis $\mathrm{FeO} 28.78$ per cent, $\mathrm{Fe}_{2} \mathrm{O}_{3} 5^{2.2}$ per cent; the rest was $\mathrm{SiO}_{2}, \mathrm{TiO}_{2}, \mathrm{Al}_{2} \mathrm{O}_{3}, \mathrm{~V}_{2} \mathrm{O}_{5}, \mathrm{MnO}, \mathrm{CaO}, \mathrm{MgO}$, $\mathrm{K}_{2} \mathrm{O}, \mathrm{Na}_{2} \mathrm{O}$, and $\mathrm{P}_{2} \mathrm{O}_{5}$. With the exception of the $\mathrm{V}_{2} \mathrm{O}_{5}$, which is reduced to $\mathrm{V}_{2} \mathrm{O}_{3}$, these are all substances not reduced by hydrogen under the conditions used in these investigations. (See Cain and Pettijohn, loc. cit.) Water calculated as equivalent to I $g$ of ore $=0.2390 \mathrm{~g}$.

(b) Sibley Iron Ore, Bureau of Standards Analyzed Sample No. 27. - Certificate analysis Fie 69.2 per cent; $\mathrm{P} 0.037$ per cent; $\mathrm{SiO}_{2}$ 
0.77. Assuming all the $\mathrm{Fe}$ to be present as $\mathrm{Fe}_{2} \mathrm{O}_{3}$ the water calculated as equivalent to $\mathrm{I} g$ of ore $=0.3345 \mathrm{~g}$.

(c) Acheson Graphite, Powdered.-This contained about 99.5 per cent carbon.

(d) White Cast Iron. - Total carbon 3.98 per cent graphitic carbon 0.02 per cent; combined carbon (by difference) 3.96 per cent.

\section{REDUCTION EXPERIMENTS WITH MIXTURES OF IRON OXIDE AND GRAPHITE-CONSTANT RATE OF PASSING HYDROGEN}

Mixtures of the magnetite and Sibley ores with graphite, as shown in Table $I$, were reduced at $900^{\circ}$, passing hydrogen at the rate of 2 liters per hour. The reaction was studied by determining the amounts of water formed.

TABLE 1.-Reduction of Mixtures of Iron Oxide and Graphite

\begin{tabular}{|c|c|c|c|c|c|}
\hline Ore used & $\begin{array}{c}\text { Weight of } \\
\text { ore }\end{array}$ & $\begin{array}{c}\text { Carbon in } \\
\text { murture }\end{array}$ & $\begin{array}{c}\text { Water } \\
\text { calculated }\end{array}$ & $\begin{array}{l}\text { Water } \\
\text { found }\end{array}$ & $\begin{array}{l}\text { Water } \\
\text { recovered }\end{array}$ \\
\hline & $\mathbf{g}$ & Per cent & $\mathbf{g}$ & $\mathbf{g}$ & Per cent \\
\hline 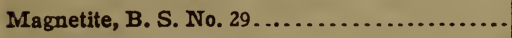 & 0.3002 & 0.00 & 0.0718 & 0.0722 & 100.4 \\
\hline Do $\ldots . . . . . . . . . . . . . . . . . . . . .$. & .0984 & .00 & .0235 & .0232 & 98.4 \\
\hline Sibley ore, B. S. No. $27 .$. & .1011 & .00 & .0338 & .0335 & 99.2 \\
\hline Magnetite, B. S. No. $29 . \ldots \ldots \ldots \ldots \ldots$ & .1007 & 3.70 & .0232 & .0234 & 100.8 \\
\hline 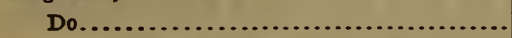 & .1001 & 26.00 & .0231 & .0232 & 100.3 \\
\hline 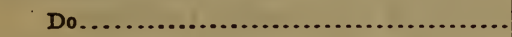 & .1007 & 65.00 & .0232 & .0232 & 100.0 \\
\hline
\end{tabular}

These results show that graphite under these conditions exerts no reducing action on the iron oxide, all the reduction being performed by the hydrogen.

\section{REDUCTION EXPERIMENTS WITH MIXTURES OF IRON OXIDE AND IRON CONTAINING IRON CARBIDE (COMBINED CARBON)-CONSTANT RATE OF PASSING HYDROGEN}

A mixture of $4 \mathrm{~g}$ of the Sibley ore with $\mathrm{I} \mathrm{g}$ of graphite was heated for 20 hours at $900^{\circ}$ with hydrogen passing until the escaping gas no longer gave a test for water; the mixture was cooled in the furnace under hydrogen and then pulverized. This operation gave an iron high in combined carbon.

Mixtures of this substance with the magnetite ore in the proportions shown in Table 2 were prepared, reduced as described in section 4 , and the amounts of water formed in each experiment noted. 
TABLE 2.-Reduction of Mixtures of Iron Oxide and "Cemented" Iron

[Amount of $\mathrm{H}_{2}$ constant]

\begin{tabular}{|c|c|c|r|r|}
\hline $\begin{array}{c}\text { Weight of } \\
\text { magnetite } \\
\text { ore }\end{array}$ & $\begin{array}{c}\text { Weight of } \\
\text { cemented } \\
\text { material }\end{array}$ & $\begin{array}{c}\text { Water } \\
\text { calculated }\end{array}$ & $\begin{array}{r}\text { Water } \\
\text { recovered }\end{array}$ & $\begin{array}{c}\text { Water } \\
\text { recovered }\end{array}$ \\
\hline $\mathrm{g}$ & $\mathrm{g}$ & $\mathrm{g}$ & $\mathrm{g}$ & Per cent \\
0.1004 & 0.1400 & 0.0240 & 0.0232 & 96.6 \\
.1008 & .1450 & .0241 & .0230 & 95.5 \\
.1005 & .2015 & .0240 & .0226 & 94.2 \\
.1002 & .3504 & .0240 & .0176 & 73.4 \\
.1004 & .4911 & .0240 & .0157 & 65.5 \\
\hline
\end{tabular}

The results of Table 2 show that the amount of water decreases as the proportion of "cemented iron" increases in the mixtures, which show that the carbon in the mixture has partially reduced the iron oxide.

\section{REDUCTION EXPERIMENTS WITH MIXTURES OF IRON OXIDE AND CHILLED CAST IRON, PARTIALIY ANNEALED AND UNANNEALED- CONSTANT RATE OF PASSING HYDROGEN}

Mixtures of the annealed and unannealed iron (crushed to 80 mesh) and magnetite ore as shown in Table 3 were prepared and reduced in hydrogen at $900^{\circ}$, the water being collected and weighed. The rate of passage of the hydrogen in the experiments described in Table 3 was the same-about I liter per hour. The cast iron was a convenient material to use for these experiments, since it contained a known large amount of combined carbon.

TABLE 3.-Reduction Experiments with Mixtures of Iron Oxide and Cast Iron

[Amount of $\mathrm{H}_{2}$ constant]

A. PARTIALLY ANNEALED IRON $a$

\begin{tabular}{|c|c|c|c|r|}
\hline $\begin{array}{c}\text { Weight of } \\
\text { ore }\end{array}$ & $\begin{array}{c}\text { Weight of } \\
\text { cast iron }\end{array}$ & $\begin{array}{c}\text { Water cal- } \\
\text { culated }\end{array}$ & $\begin{array}{c}\text { Water re- } \\
\text { covered }\end{array}$ & $\begin{array}{r}\text { Water re- } \\
\text { covered }\end{array}$ \\
\hline $\mathbf{g}$ & $\mathbf{g}$ & $\mathbf{g}$ & $\mathbf{g}$ & Per cent \\
0.1007 & 0.2652 & 0.0241 & 0.0194 & 80.5 \\
.1000 & .4496 & .0239 & .0163 & 68.2 \\
.1000 & .4725 & .0239 & .0108 & 45.2 \\
.1006 & .4727 & .0240 & .0109 & 45.4 \\
.1005 & .5880 & .0240 & .0092 & 38.0 \\
\hline
\end{tabular}

B. UNANNEALED IRON

\begin{tabular}{|r|r|r|r|r|}
\hline 0.1002 & 0.2007 & 0.0239 & 0.0107 & 44.9 \\
.1001 & .4006 & .0239 & .0093 & 38.9 \\
.1000 & .5020 & .0239 & .0057 & 23.8 \\
\hline
\end{tabular}

a The oxygen content of the iron before annealing was 0.034 per cent. This iron was only partially annealed, which explains the $A$ and $B$ results of the above table. 
These results show that the yield of water diminishes as the proportion of cast iron in the mixtures increases and that the specific effect of unannealed iron is greater than that of the annealed iron. The carbides in the iron seem to be responsible for the disturbance of the reaction.

7. REDUCTION EXPERIMENTS WITH MIXTURES OF UNANNEALED CAST IRON AND IRON OXIDE-RATE OF PASSAGE OF HYDROGEN VARIED

The details of these experiments are shown in Table 4 and in Fig. 2. The amounts of water recovered increased with all mix-

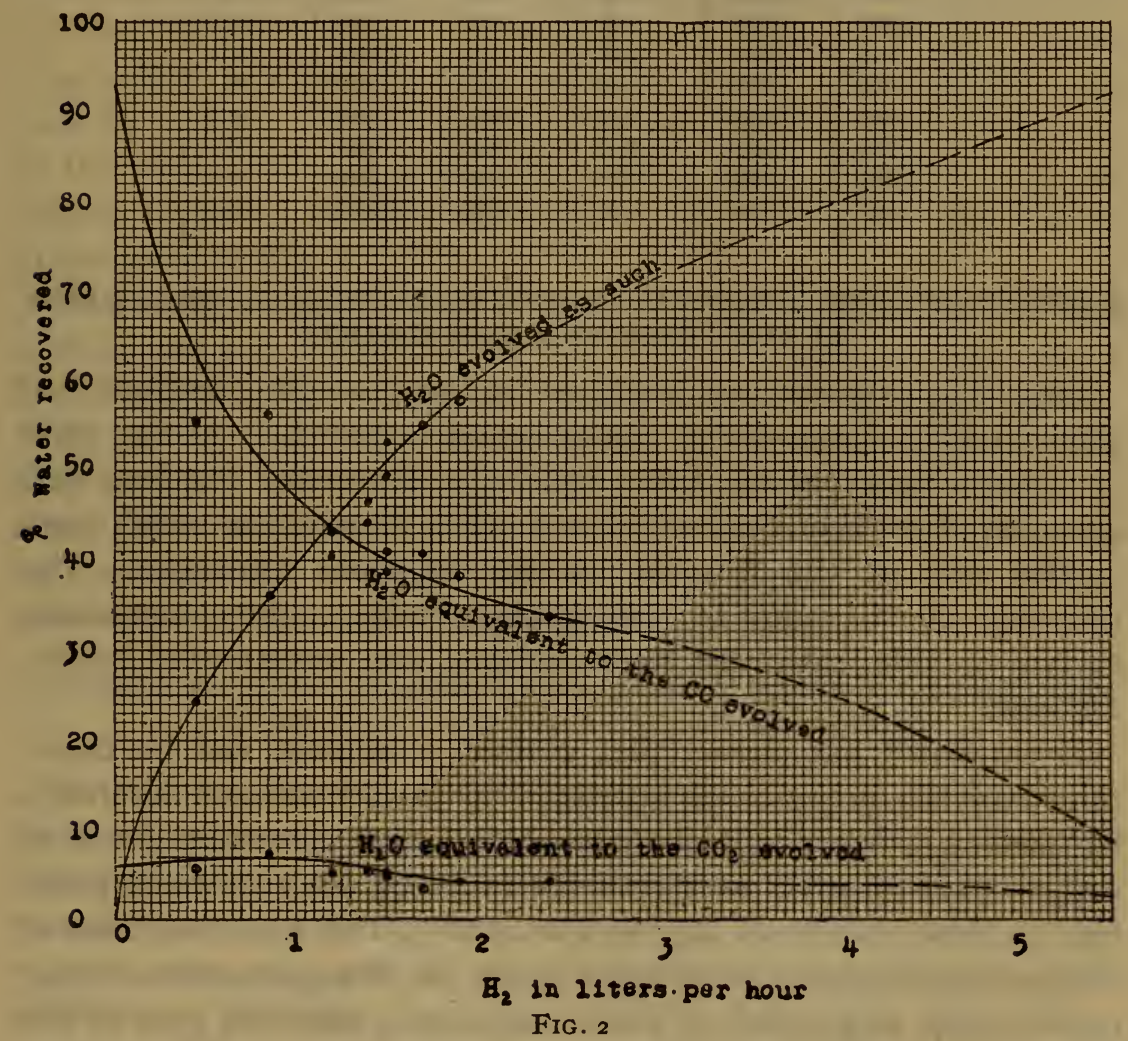

tures as the rate of passing hydrogen increased and approached a maximum limit at the rate of 3 liters per hour. As shown by Fig. 2, it would be impossible to recover more than 75 per cent of the water when the ratio of ferrous oxide to carbon (combined) is I to 5. In any steel the proportion of carbon relative to ferrous oxide is much greater than this, hence it seems very probable from these experiments that the Lerlebur method can not determine more than 75 per cent of the oxygen in steels and that the actual recovery will be much less if hydrogen is passed too slowly. 
TABLE 4.-Reduction of a Mixture of Iron Oxide and Unannealed Chilled Iron

[Amount of hydrogen varied]

\begin{tabular}{|c|c|c|c|c|c|}
\hline $\begin{array}{c}\text { Weight of } \\
\text { ore (B.S. } \\
\text { No. 29) }\end{array}$ & $\begin{array}{c}\text { Weight of } \\
\text { cast iron }\end{array}$ & Speed & $\begin{array}{c}\text { Water cal- } \\
\text { culated }\end{array}$ & $\begin{array}{c}\text { Water re- } \\
\text { covered }\end{array}$ & $\begin{array}{r}\text { Water re- } \\
\text { covered }\end{array}$ \\
\hline $\mathrm{g}$ & $\mathrm{g}$ & Liter/hour & $\mathrm{g}$ & $\mathrm{g}$ & Per cent \\
0.2002 & 1.0010 & 0.30 & 0.0478 & 0.0102 & 21.3 \\
.2007 & 1.0010 & .45 & .0480 & .0116 & 24.2 \\
.2001 & 1.0050 & .85 & .0478 & .0173 & 36.2 \\
.2005 & 1.0004 & 1.20 & .0480 & .0194 & 40.4 \\
.2003 & 1.0000 & 1.40 & .0479 & .0223 & 46.6 \\
.2001 & 1.0000 & 1.50 & .0478 & .0254 & 53.2 \\
.2000 & 1.0006 & 1.70 & .0478 & .0263 & 55.0 \\
.2000 & 1.0007 & 1.90 & .0478 & .0276 & 57.8 \\
.2000 & 1.0002 & 2.40 & .0480 & .0313 & 65.4 \\
.2002 & 1.0000 & 3.10 & .0480 & .0319 & 66.5 \\
.2000 & 1.0000 & 3.30 & .0480 & .0339 & 70.7 \\
.2004 & 1.0000 & 4.70 & .0482 & .0349 & 72.5 \\
.2007 & 1.0000 & 6.30 & .0482 & .0352 & 73.0 \\
\hline
\end{tabular}

\section{INVESTIGATIONS CONCERNING THE OXYGEN NOT EVOLVED AS WATER IN THE PRECEDING EXPERIMENTS}

Since the experiments described in the preceding sections had shown such a large deficit under certain conditions in the yield of water to be expected, it was decided to determine the form and amounts of some of the compounds other than water which were carried out of the furnace by the escaping hydrogen. The probable constituents in this mixture were carbon monoxide, carbon dioxide, saturated hydrocarbons, and unsaturated hydrocarbons.

Nesmjelow ${ }^{13}$ has shown that carbon monoxide can be determined in the presence of saturated hydrocarbons and hydrogen by passing oxygen and the gaseous mixture several times over copper oxide heated to $250^{\circ}$. Unsaturated hydrocarbons interfere to some extent in this determination, but the conditions of these experiments seemed unfavorable for the production of any considerable proportion of such compounds, and this part of the work was carried out on this assumption. The total amount of saturated hydrocarbons (which was accurately determined, see later paragraphs), as shown in Table 5, was very small; hence the assumption that the per cent of unsaturated hydrocarbons was still smaller seems justified.

Preliminary tests of Nesmjelow's method confirmed his results, and this method was accordingly adopted for the study. The apparatus for these determinations followed the phosphorus 
pentoxide tube shown at $U$ in Fig. I, and consisted of (I) a Meyer tube filled with barium hydroxide to absorb the carbon dioxide, (2) an electrically heated, hard-glass combustion tube filled with copper oxide maintained at a temperature of $250^{\circ}$, (3) a Meyer tube filled with barium hydroxide solution for absorbing the carbon dioxide produced in the copper oxide tube, (4) a porcelaincombustion tube heated to $850^{\circ}$ for oxidizing the saturated hydrocarbons, and (5) a Meyer tube filled with barium hydroxide solution for collecting the carbon dioxide generated in this furnace. The barium carbonate in the various Meyer tubes was determined by the titration method. ${ }^{14}$ The results are shown in Table 6 , which is arranged to show the total recovery of the carbon in the solid gaseous phases. This was done by determining the carbon left in the solid substance after each experiment and adding to it the carbon found in the gaseous phase. The results are also shown graphically in Fig. 2.

These experiments show that the greater proportion of the missing oxygen excapes as carbon monoxide, and that this effect is minimized by increasing the rate at which the hydrogen passes. If the carbon monoxide and carbon dioxide curves are extrapolated they intersect the horizontal axis at about 5 ; in other words, if hydrogen were passed at the rate of 5 liters per hour, or faster, no carbon monoxide or dioxide would be produced. It is doubtful, however, whether such extrapolation is justified.

\section{OXYGEN DETERMINATIONS BY THE LEDEBUR METHOD ON THE SAME STEELS WITH VARYING RATES OF HYDROGEN}

In order to show the specific application of the preceding work to the determination of oxygen in steels by Ledebur's method, determinations were made on several steels when hydrogen was passed at rates varying from 0.7 to 5.3 liters per hour. The samples were prepared by cutting under oil and with the other precautions described by Cain and Pettijohn (loc. cit.). The results are shown in Table 7 and bring out quite clearly the necessity for a rapid current of hydrogen.

14 J. R. Cain, Bureau of Standards Technical Paper No. 33; r9r4. 


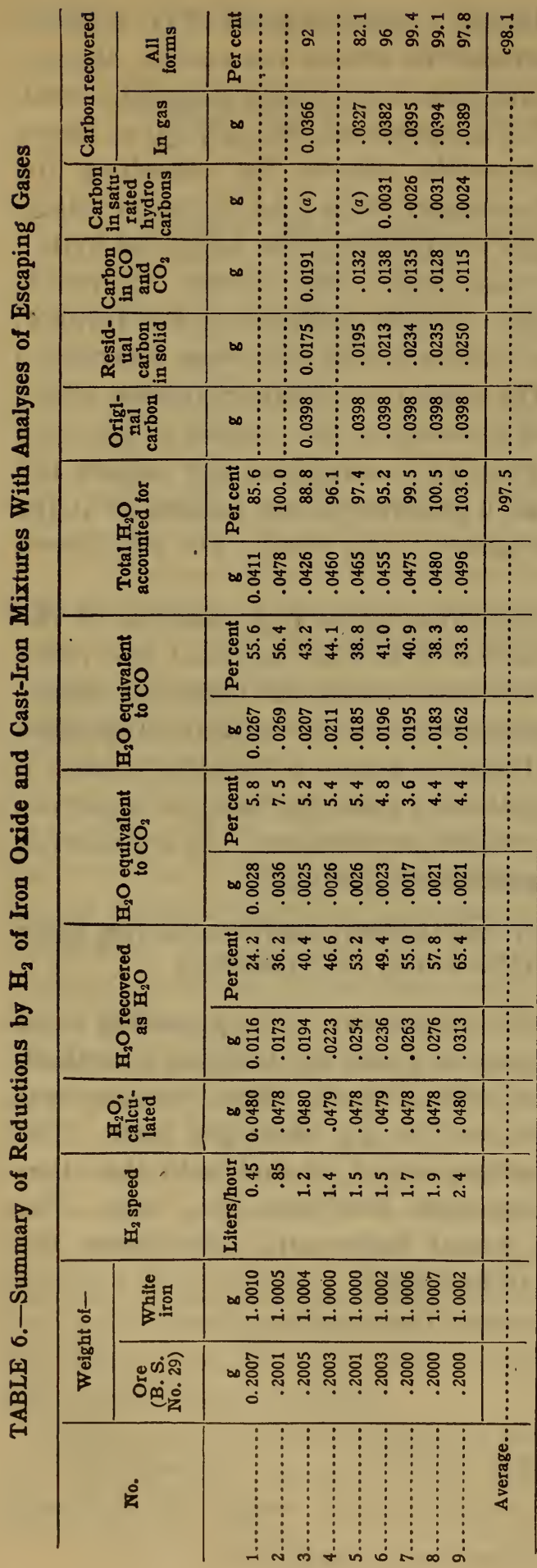


TABLE 7.-Oxygen Determinations on Steels; Variable Amounts of Hydrogen Used

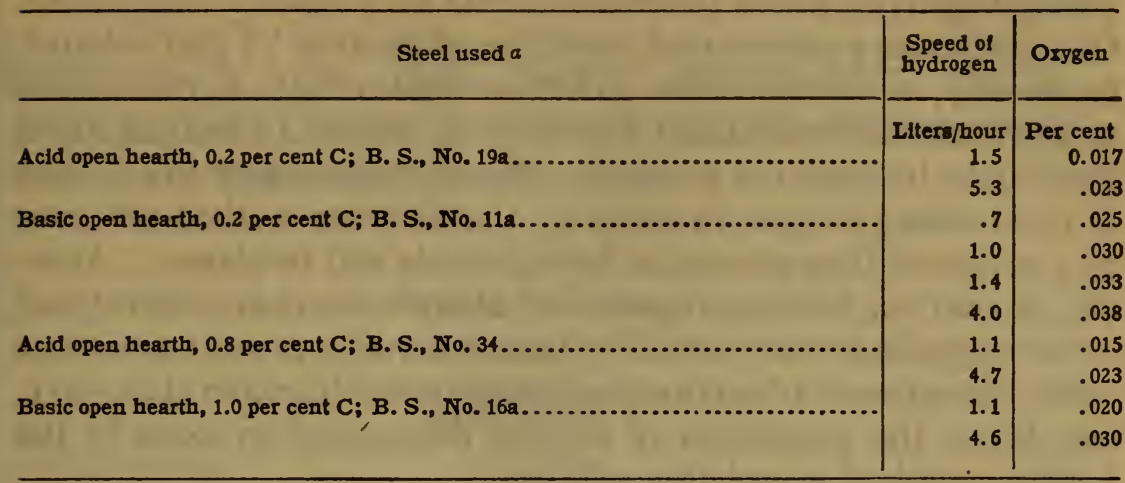

a All were Bureau of Standards analyzed samples.

\section{GENERAL DISCUSSION}

Considering the experimental results of this paper in relation to some of the reactions given in the introductory section, it is evident that the rate of hydrogen passage affects certain of the reactions and has no effect, or only minor effect, on others. Reactions (2), $\mathrm{FeO}+\mathrm{C} \rightleftarrows \mathrm{Fe}+\mathrm{CO}$, and (3), $\mathrm{FeO}+\mathrm{CO} \leftrightarrows \mathrm{Fe}+\mathrm{CO}_{2}$, would tend to produce larger amounts of carbon monoxide with increase in hydrogen rate, which is contrary to the experimental results obtained. Hence under the experimental conditions herein described these reactions are not much affected. The equilibrium of reaction $(4), 2 \mathrm{CO} \rightleftarrows \mathrm{CO}_{2}+\mathrm{C}$ (i. e., thermal dissociation of carbon monoxide), would be shifted toward the left with rapid hydrogen passage, a result in conformity with what was found. Reaction (6), $\mathrm{CO}_{2}+\mathrm{H}_{2} \rightleftarrows \mathrm{CO}+\mathrm{H}_{2} \mathrm{O}$, tends to proceed toward the right in the $900^{\circ}$ zone of the furnace; hence a rapid current of hydrogen would have the effect of suppressing production of carbon monoxide by this reaction since the reacting substances would thus be carried away rapidly from the reaction zone. This expectation is also borne out by the results of this paper. Reactions (7), $\mathrm{CO}+\mathrm{H}_{2}=\mathrm{H}_{2} \mathrm{O}+\mathrm{CxHy}$, and (9), $\mathrm{C}+\mathrm{H}_{2}=\mathrm{Cx}^{\prime} \mathrm{Hy}^{\prime}$, do not seem to be greatly affected, as shown in experiments $6,7,8$, and 9 of Table 6 , by variation of the hydrogen rate. No conclusions regarding these reactions could be drawn, however, without further work.

Reaction (8), $\mathrm{C}+\mathrm{H}_{2} \mathrm{O} \rightleftarrows \mathrm{CO}+\mathrm{H}_{2}$, is the one most affected by the amount of hydrogen passed, its shift being toward the left, in conformity with theory. As shown in Table 4, the equilibrium for this equation under conditions described in Section VI permits no 
more than 75 per cent of the reduction of the ferrous oxide to be affected by hydrogen in the reaction $\mathrm{FeO}+\mathrm{C}+\mathrm{H}_{2} \rightleftarrows \mathrm{Fe}+\mathrm{H}_{2} \mathrm{O}+\mathrm{CO}$. One particular experimental condition of Section VI just referred to, namely, a ratio of carbon to ferrous oxide of 5 to $I$, was chosen to simulate to some extent the ratio of carbon to ferrous oxide that might be expected in steels. Hence it seems safe to say that in determining oxygen in steels by the Ledebur method not over 75 per cent of that present as ferrous oxide will be shown. Actually, if analyses hitherto reported by other workers are correct and if the oxygen in steels reported by them was really present as ferrous oxide, the ratio of carbon to oxide in steels is much greater than 5 to $\mathrm{I}$, and hence the proportion of oxygen determined in steels by the Ledebur method is probably still less.

\section{CONCLUSIONS}

I. Graphite does not reduce ferrous oxide or water vapor at $900^{\circ}$ if hydrogen is passing at the rate of 2 liters or more per hour.

2. Combined carbon in iron reduces ferrous oxide (with formation of carbon monoxide) under the conditions given in conclusion I, to an extent varying with the proportion of carbide present.

3. The percentage of ferrous oxide reduced by hydrogen from a mixture of iron carbide with ferrous oxide is a function of the rate of passage of the hydrogen, and, as shown by experiments in this paper, reaches a maximum of 75 per cent reduction when hydrogen passes at about 3 liters per hour. The remaining oxygen is evolved principally as carbon monoxide and partly as carbon dioxide.

4. The Ledebur method under most favorable conditions probably can not account for more than 75 per cent of the oxygen present in a steel as ferrous oxide.

WASHINGTON, January I 8, I9I9. 